\title{
Good bye Lenin! Reflexiones en torno a un discurso consciente de época
}

\author{
Norberto Leonardo Murolo \\ (Universidad Nacional de La Plata)
}

Recibido: 20/12/2010

Aceptado: 29/1/2011

\begin{abstract}
Resumen: El filme Good bye Lenin! (2002), de Wolfgang Becker, supone una reflexión acerca de los hechos acontecidos en la historia reciente alemana. El muro de Berlín como emblema, su caída y la unificación de los ochenta/noventa son temas que calan profundo en la identidad alemana. Partiremos de un necesario repaso histórico que nos sumerge en el discurso de Good bye Lenin! como un producto cultural crítico y consciente de época, para poder reflexionar acerca de la mirada, entre intelectual y artística, que propone el director.
\end{abstract}

Palabras clave: filme / cambio de época / narración audiovisual

\section{Good bye Lenin! Reflections around a conscious epoch discourse}

Summary: The film Good bye Lenin! (2002), by Wolfgang Becker, is a reflection on the events in recent history in Germany. The Berlin Wall as an emblem, his fall and the unification of the eighties/nineties are themes that permeate deep into the German identity. Part of a necessary historical account takes us into the discourse of Good bye Lenin! as a cultural critic and conscious of time to think about the look, between intellectual and artistic, as proposed by the director.

Keywords: film / new era / audiovisual narration 
La época del capitalismo moderno nos muestra que entre los grupos capitalistas se están estableciendo determinadas relaciones sobre la base del reparto económico del mundo y que, al mismo tiempo, en conexión con esto, se están estableciendo entre los grupos políticos, entre los Estados, determinadas relaciones sobre la base del reparto territorial del mundo, de la lucha por las colonias, de la lucha por el territorio económico.

V. I. LENIN, 1916

\section{Introducción histórica}

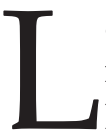

a República Democrática Alemana (RDA) surgió en 1949 tutelada por la Unión de Repúblicas Socialistas Soviéticas (URSS) como respuesta al establecimiento de Alemania Occidental, patrocinada por los países aliados democráticos, según lo acordado en 1945 en las conferencias de Yalta y Potsdam, y aplicó los principios políticos del socialismo soviético.

Durante la década de 1950, las relaciones entre Alemania Oriental y Alemania Occidental se hicieron tensas después de que el canciller de la República Federal Alemana, Konrad Adenauer, afirmara que todos los alemanes formaban una sola nación. Las relaciones se hicieron más tensas con la división de Berlín en dos zonas.

Aunque Berlín, ciudad en la que viven los protagonistas de Good bye Lenin!, se encontraba dentro del territorio de la República Democrática Ale- mana, había sido dividida en el sector este (bajo control soviético) y oeste (dependiente de las potencias aliadas occidentales).

Cristianne (Katrin Sass), el personaje principal, es una mujer que vive con sus dos hijos en Berlín Oriental; ferviente socialista, nacida en la RDA por estos años, donde el gobierno era llevado adelante por Ulbrich, quien para detener la corriente de alemanes orientales -que insatisfechos con la nueva situación escapaban a Occidente-, estableció un corredor a lo largo de la frontera occidental del país, dejando a Berlín como única ruta de escape. Ulbrich finalmente bloqueó esa salida en 1961 al ordenar la construcción del Muro de Berlín, una barrera de cemento que separaba Berlín Oriental de Berlín Occidental.

En su adolescencia y juventud, Cristianne probablemente haya creado lazos que la ligaron fuertemente a la ideología socialista, viéndose favorecida por aquel Estado Benefactor que, gracias al nuevo sistema económico implantado desde 1963, hizo posible la recuperación económica de Alemania del Este, mejorando los ingresos y los beneficios de los trabajadores y facilitando a muchos una educación tecnológica avanzada. Sin embargo, fue en 1978, a raíz de que su marido la abandonó y viajó a Occidente, cuando ella "se casó" con la patria socialista, afianzando los lazos con su país y distanciándose aún más del Occidente que le quitó a su marido. 
Desde 1968 hasta 1989, Alemania Oriental fue gobernada bajo una Constitución que garantizaba al partido un papel fundamental en los asuntos nacionales, y su secretario general, jefe del Politburó del Partido Socialista Unificado de Alemania (SED, por sus siglas en alemán), era la persona más poderosa del país. Se definía al país como un Estado soberano socialista, en el que todo el poder político era ejercido por el pueblo trabajador. De hecho, el verdadero poder residía en el SED.

El filme se centra en la vida de Cristianne y comienza en la infancia de su hijo Álex Kerner (Daniel Brühl), hacia fines de la década de 1970. Allí podemos ver de qué modo Cristianne se muestra como una militante comprometida, tomando posición activa en las cartas que envía al Estado Benefactor que los cobija, donde los camaradas son miembros de una comunidad ideal, y donde la TV muestra a esa RDA superior, que llega incluso al espacio, es el deleite lúdico de niños como Álex, y el orgullo político de militantes como su madre. Siendo un país bajo la égida de la URSS, la RDA veía con importancia los cambios sufridos en la cúpula del PCUS. Y, luego de los años de Kruschev, donde la Guerra Fría se afianzó, se llevó a cabo el VI Plan Quinquenal, y la carrera espacial fue posible; pasando por el mandato de Breshnev donde las prácticas rígidas volvieron a aparecer, llegamos al año 1985, donde, luego de la muerte de Andropov, Gorbachov se convirtió en secretario general del PCUS. Después de que Andréi A. Gromiko se retirara como presidente soviético, Gorbachov también asumió este cargo, en su calidad de presidente del Presidium del Soviet Supremo. Desde su nueva posición llevaría adelante medidas liberadoras de la economía soviética, lo que se dio en llamar "perestroika" y otro conjunto de medidas en el terreno de la política y la cultura conocidas como "glasnot", que prepararon al país para las reformas democráticas y relajaron las tensiones con Occidente, especialmente con Estados Unidos. En 1987 Gorbachov y el presidente de Estados Unidos, Ronald Reagan, firmaron un acuerdo para destruir los misiles terrestres de medio y corto alcance.

\section{Mientras dormía}

Las reformas que implementó Gorbachov trajeron aparejado el creciente reclamo de mayores libertades por parte de los países de Europa Central y de Europa del Este que se encontraban bajo la tutela de Moscú. Justamente, Cristianne sufrió un infarto el 7 de octubre de 1989, cuando presenciaba el momento en que detenían a su hijo Álex durante una manifestación a favor de la libertad de prensa en la RDA. Por esos días, se conmemoraba el cuarenta aniversario de la República, y los festejos traerían consigo el repentino y mentado comienzo del cambio.

Durante los ocho meses siguientes que Cristianne se encontraría en 
coma, en la RDA sucederían cambios importantes en los órdenes político y social que llevarían al fin del socialismo y a la apertura de una economía de mercado. A los pocos días de lo sucedido a Cristianne, materializando las consecuencias de las medidas de Gorbachov, se abrió el Muro de Berlín, que rápidamente fue desmantelado por la multitud. Las otras barreras a la emigración también cayeron, y cientos de miles de alemanes orientales salieron hacia Berlín Occidental. Mientras tanto, las revelaciones de corrupción entre los funcionarios superiores durante la época del gobierno de Honecker supusieron la desaparición del Partido. En esos momentos, Álex y su hermana experimentaron la nueva vida occidentalizada que trajo consigo el paso a la otra Alemania, el cambio de las costumbres de vida y la adopción de la moda y del tan ansiado consumo.

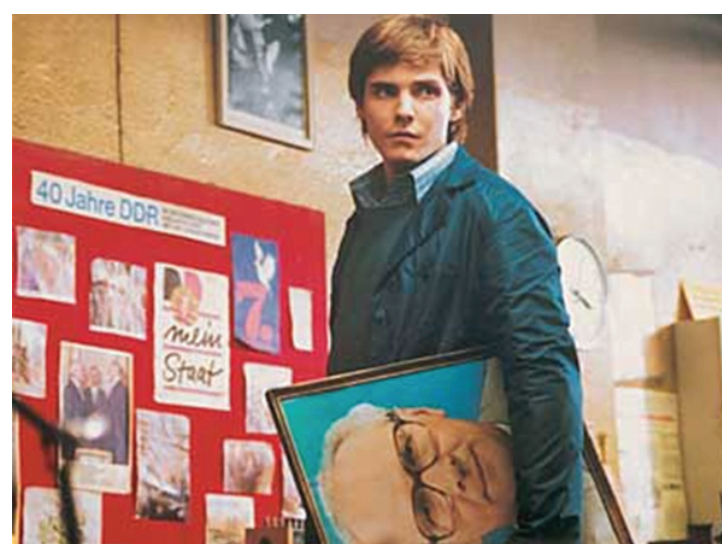

Álex ha descolgado el retrato del "camarada" Honecker tras su renuncia.
El gobierno comunista se deshizo a fines de 1989, después de que Hungría cancelara un acuerdo establecido veinte años atrás con Alemania Oriental, permitiendo a miles de ciudadanos germanoorientales cruzar su frontera para llegar a Austria y de ahí pasar a Alemania Occidental, donde se les daba asilo. A raíz de la crisis política de 1989, Honecker, quien había ocupado el cargo desde 1971, fue forzado a dimitir de la presidencia y Egon Krenz se convirtió en jefe del Estado y en secretario general del Partido. Al no poder enfrentarse al creciente descontento popular, Krenz cesó en sus cargos en diciembre de 1989. Cedió a las demandas de los grupos de oposición y se celebraron elecciones libres para una nueva Cámara Popular. A este organismo de transición, elegido libremente en marzo de 1990, se le encargó la elaboración de los arreglos constitucionales bajo los que la RDA se fusionaría con la República Federal de Alemania.

Podemos ver, entonces, que cuando Cristianne despertó del coma, el mundo a su alrededor ya no era el mismo: miles de productos occidentales invadían las calles de Berlín Este, incluso su hija dejó la carrera de ingeniería para trabajar en un Burger King. Igualmente, ella no se enteraba de todos los cambios dado que mientras tanto, por recomendación de los médicos, quienes sostuvieron que Cristianne no soportaría emociones fuertes, y sabiendo que el frágil co- 
razón de su madre sería incapaz de superar tantos cambios, Álex decidió ocultarle la verdad, y construyó a su alrededor una ilusión en la que la Alemania socialista seguía estando viva.

Las dos repúblicas unieron sus sistemas financieros en julio de 1990, el nuevo cambio fue de dos a uno, y los hijos de Cristianne, mediante mentiras, le pedían sus ahorros para realizar la transacción. Cristianne no recordaba dónde había guardado su dinero y cuando logró recordar ya fue tarde y perdieron los ahorros. Esta unión de sistema monetario presagió que finalmente, en octubre de 1990, se disolvería la RDA y se integraría en la RFA, produciéndose así la reunificación alemana.

La coalición liderada por la Unión Demócrata Cristiana y dirigida por el canciller alemán occidental Helmut Kohl obtuvo una victoria en las elecciones legislativas celebradas en diciembre de 1990, lo que le permitió a Kohl convertirse en canciller de la Alemania unificada.

Vemos cómo la Alemania que Álex creó para su madre poco tenía que ver con la realidad de la RDA. Lejos de los excesos autoritarios del régimen comunista y de las inestabilidades y las injusticias del capitalismo, Álex construyó en la habitación de su madre una Alemania idealizada, en la que la Coca Cola se convirtió en un invento socialista y miles de ciudadanos de la
RFA saltaban el muro huyendo de la presión de la vida moderna en las sociedades occidentales. Y en torno a la habitación comenzaron a congregarse muchos de sus amigos y vecinos, no tanto por nostalgia del régimen anterior sino por su incapacidad de aceptar la súbita imposición de los modelos culturales que en cuestión de meses cambiaron por completo el panorama de Alemania del Este.

Finalmente, Cristianne murió, quizás sabiendo la verdad que su hijo le dibujaba con el ideal de aquella Alemania que los hizo felices, tapando lo desagradable de un mundo inevitable y emprendiendo un viaje hacia el cielo, despegando de la nueva realidad que le era ajena.

\section{Del mito al logos}

El proceso de unificación alemana se produjo en 1990, pero trajo consigo toda una reflexión y un volver a vivir el pasado. Todo lo bueno y lo malo era válido, en esa ocasión, para formar una opinión sobre lo inminente que cambiaría la vida de los alemanes en su conjunto. Ese momento, desde la historiografía, se propone como un eje que cambia la edad histórica. Sin dudas, es un punto de inflexión que catalizaría el devenir de un nuevo tipo de sociedad que cimentará y afianzará lo que diversos autores denominan posmodernidad, hipermodernidad, 
sobremodernidad. ${ }^{1}$ Zygmunt Bauman (2002) llama "modernidad líquida" a este estadio histórico donde las relaciones institucionales y humanas son cambiantes y regidas por el mercado. La importancia del postulado de Bauman radica en que ubica este estadio dentro de la modernidad, no luego de esta.

En Good bye Lenin!, el realizador fluctúa con el tiempo en sus visiones del proceso. Para dejar en claro la actitud de Becker ante la unificación alemana, asemejaríamos su visión al personaje de Álex, quien oscila entre un amor-odio en lo referente a los dos mundos que existen en la Alemania, próximos a ser uno solo. Dice Sarlo:

La pérdida de sentidos no tiene que ver sólo con el estallido presente sino con la sombra que lo acompaña: el olvido de la historia y la experiencia de un tiempo que "ha dejado de ser tiempo histórico" y, en consecuencia, no mantiene lazos con el pasado ni hace promesas de continuidad futura. (Sarlo 2004: 192).

Intentamos advertir la postura intelectual de Becker, quien planteando una conciencia de época, nos presenta un aquí y ahora confuso, como la realidad. Becker propone un rescate de la historia con los condimentos racionales y sentimentales que puede aprehender y hacer aprehender quien lo vivió.
En su primera infancia comenzó a ser absorbido de manera inconsciente por la ideología socialista, la ilusión por cambiar el mundo y por crear una realidad más digna y creíble que la de su adversario ideológico. Si bien hablamos de su infancia, y en ella no hubo más que vida socialista, podemos extender, de algún modo, esta cercanía a su "vida materna" cuando los dos mundos llegan a su aprehensión. Demostrándonos lo contrario hallamos la postura de su hermana, quien, viviendo la misma realidad que Álex, podríamos asemejarla a su padre en cuanto opta por la oportunidad que se presenta para renunciar a su "vida materna" y adoptar el modo de vida alienado de Burger King, tanto como la superación inmediata que le trae la vestimenta moderna y la televisión occidental.

Era natural, en la infancia de Álex, jugar con una vida espacial tangible, que se veía por televisión, pero que también era de carne y hueso, donde un astronauta como Sigmund Jähn era su héroe, y su ideal. Donde el socialismo superaba las fronteras de este mundo y ganaba aún más legitimidad y apoyo de sus apasionados seguidores.

De este modo, cara a 1990, vemos a otro Álex, comprendiendo que la realidad actual no bastaba para completar una totalidad de vida favorable, donde las manifestaciones por la libertad

1 Conceptos acuñados por los pensadores Jean Françoise Lyotard, Gilles Lipovetsky y Marc Augé. 
enfrentan su historia familiar con el ansia de un ideal de mayor autonomía. Y es así como, casi desilusionado pero no vencido, se enfrentaría a una prueba que lo hará repensar su actualidad y regresar a los (ahora) añorados años felices, cuando comenzara a dibujar un universo que se diluye como acuarelas en la lluvia, para su madre enferma. Asistimos a todo lo románti$\mathrm{co}$, inconsciente e irracional que tiene este mundo que parecía sólido, y que se iguala al mundo interno del propio Álex, quien no solo agota sus fuerzas regalándole unos últimos días de vida socialista a su madre, sino que también se sorprende construyéndolos para él. Si "toda expresión de la vida espiritual humana puede ser concebida como una especie de lenguaje, y esta concepción plantea -como todo método verdadero- múltiples problemas nuevos" y si "toda comunicación de contenidos espirituales es lenguaje" (Benjamin 2004: 91), Álex hace uso de un lenguaje familiar, utópico y en extinción, el cual va conociendo de manera intrínseca, mientras se va alfabetizando en él. Allí estriba el mayor recurso de conciencia de época que Becker, como intelectual, nos dibuja mediante el lenguaje audiovisual: Álex advirtiendo lo importante de su pasado en esa representación y descubriendo que más difícil que advertir los cambios paulatinos mientras se van dando, es advertir que algo está cambiando.

La construcción de la Alemania extinta, por parte de Álex, consiste

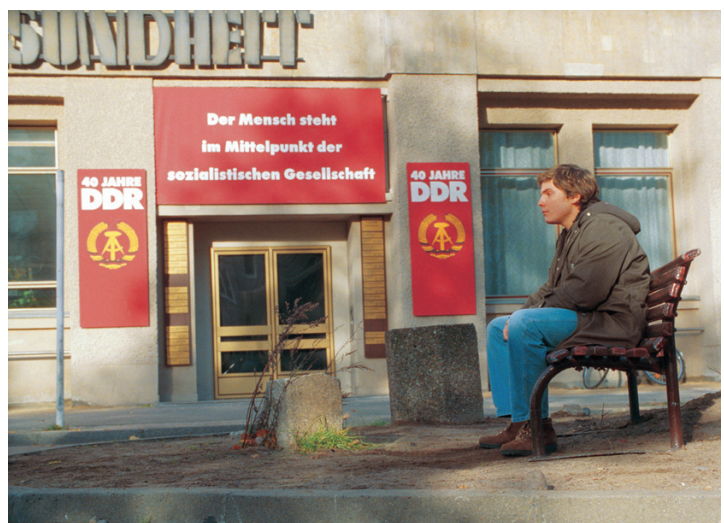

Álex (Daniel Brül) en una calle de Berlín Oriental.

en recrear el escenario de la habitación de su madre con los muebles que habían descartado, convocar a niños para que entonen las canciones patrióticas, fabricar mediante envases usados los productos característicos de la reciente antigüedad, crear junto con su amigo cineasta amateur programas televisivos e informativos que hablen del pasado en tono de presente real: "Pasa noticias viejas, siempre pasaba lo mismo".

En este escenario: el de la nueva verdad, Sigmund Jähn no es más el héroe espacial de fines de los setenta, sino un taxista, que acepta la propuesta de convertirse por unos minutos en el nuevo presidente de la ya inexistente RDA, para el deleite televisivo de Cristianne. El mito del socialismo todopoderoso, que renegaba de toda religión para ocupar su lugar, ejerciendo la tutela de sus habitantes, beneficiándolos con su presencia omnisciente y eterna, que exigía a cambio solo una pasión revolucionaria y ser una creen- 
cia, se ve eclipsado por el logos de esta nueva realidad, donde lo intangible e ideal no tiene lugar, en donde se requiere la razón, el intercambio libre, la competencia, en lugar de la mística fe. Donde la moral se encuentra preformada y da a cambio de la adhesión una vía libre al crecimiento infinito en materia económica, da la moda, el lujo y el conformismo.

Vemos de qué modo visita Álex un enigma que seduce, que atrapa por ofrecer una vida más facilitada aunque no más fácil, repleta de consumismo y publicidad; en definitiva las mercancías de la moral, la fe y el arte al alcance del bolsillo. Un gran mercado del progreso llamado Occidente se encuentra a la vuelta de la esquina y avanza a pasos firmes, invita a ser conocido y por ello, en cuanto cae el muro, Álex cruza la frontera y se zambulle en las aguas de su futuro.

De allí que la postura de BeckerÁlex ante la unificación alemana no es otra que la de rescatar los "valores" perdidos: las marcas de los alimentos preferidos, las noticias alentadoras de un régimen preeminente, una casa del Este amueblada como en el Este en la que se habla el idioma del Este habitada por un sentimiento del Este y por sus ganas de esa prometedora infancia perdida en el tiempo.

La representación genera un volver a vivir; es un universo simbólico de donde la imagen, la palabra, los signos en general, pretenden convertirse, ya no en espejo, sino en verdad.
Ya Hamlet había impulsado una representación de la muerte de su padre, para incomodar al expectante asesino. Ver por fuera de sí, mediante una catarsis aristotélica, invita a sentir de otro modo lo cotidiano. Es en este caso un intenso grito inaudible que sublima mediante el arte, que se oye como un eco, como un incesante decir ${ }_{i} \mathrm{No}$ ! a la polarización Bueno-Malo, NuevoAntiguo, Logos-Mito. Donde la propia identidad pretende rescatar esos valores cual escombros en el derrumbe de un pasado.

Vemos a Becker-Álex perpetuar finalmente este rescate, amarrándolo en su corazón, y a la vez acostumbrándose a la nueva vida, y planteando una resignación ante lo venidero, convirtiendo en acto una mixtura de su infancia, sus deseos, la grandeza de su madre y su ejemplo, encendiendo un cohete que inmortaliza la no existencia de Cristianne en este nuevo e indiferente suelo.

La ilusión en otro mundo y la realidad en la vida parece ser la reflexión final de quien mediante el arte intelectual expresa un sentimiento de pérdida que es más que una posibilidad concreta de progreso; es más que el ansia de un ideal.

\section{Escala de grises}

Becker muestra en el filme, mediante la mirada del proceso social que cambiará el modo de vida alemana, una 
progresión de opiniones que se asemejan a las personalidades y alcances de cada personaje. Es por ello que, haciendo referencia a los principales roles del filme, a la familia central que lo protagoniza, se puede vislumbrar una gradación de posturas que dan cuenta de toda la pasión, a favor o en contra, que despierta el socialismo y su contracara, así como la negación, el tolerar, el disimular y el defender que despierta en quienes lo vivieron y quienes decidieron no vivirlo.

Hemos ubicado la postura de Becker proyectada en el personaje de Álex, quien, con arreglo a la temporalidad, oscila entre un desconocimiento, cuando niño, de lo opresora que era la sociedad socialista, disfrutando de toda la magia y mitología del régimen que en su pequeño mundo simbolizaba su madre, y una realidad de adulto que conocía el lado oscuro del socialismo, y reclama, desencantado, por mayor libertad; siendo a la vez la única luz que pretende rescatar los valores de su pasado en la niebla que la corrupción y la opresión no dejaban visualizar. Por ello, vemos que es la postura más fuerte, sugerente y que más prevalece en el filme. Sin embargo, en la amplia gama de posiciones que atraviesa la historia, en esta sutil escala de grises que propone, podemos mencionar el extremo que encarna el padre de Álex, quien huyó a Occidente hace tiempo, demostrando una inadaptación al difícil mundo socialista. "Viaja en un Volvo y usa lentes oscuros", lo describe como un "cerdo capitalista", puntualizando en la necesidad de progreso que lo llevó a planear una realidad que finalmente no fue acompañada por su esposa.

Trazando una vía en esta escala podríamos colocar un paso adelante la posición de la hermana de Álex, quien no huyó ni aparentemente intentó hacerlo, absorbiendo por costumbre aturdidora el modo de vida del Este. Se le puede oír diciendo "mira los trapos que usábamos", hablando de la vestimenta que llevaban antes de la irrupción del capitalismo, haciendo referencia a ese pasado como más lejano que lo real, y negativo. Demostrando que la occidentalización vino a actualizar una potencia oculta en ella, que se emparienta con el hastío de la vida socialista, simbolizada hace tiempo en la huida a Occidente y traducida hoy en la aceptación inmediata del modelo de consumo capitalista. El filme pone en evidencia, con las actitudes del padre y de la hermana de Álex, una marca del sistema capitalista: la distinción. Bourdieu sostiene al respecto que:

El interés que conceden las diferentes clases sociales a la propia presentación, la atención que le prestan, la conciencia que tienen de los beneficios que aquella aporta y las inversiones de tiempo, de esfuerzos, de privaciones, de cuidados que le otorgan, realmente están en proporción con la posibilidad de beneficios materiales o simbólicos que razonablemente pueden esperar de la misma; y, con mayor precisión, dependen de la existencia de un mer- 
cado de trabajo en el que las propiedades cosméticas puedan recibir un valor [...] (Bourdieu 1998: 203).

Como vimos, en un tercer estadio se encontraría la posición de Álex, como el único personaje del filme que no lee el proceso en clave de positivonegativo, sino en términos de cambio. Tiene en cuenta que algo se ha perdido, y a la vez aprovecha que la apertura trajo consigo la posibilidad de ver a su padre, y con ello, las dos mitades de su identidad vueltas a unificar.

Llegamos así al otro extremo de esta escala, personificado por la madre de Álex, de quien no sabemos cabalmente cómo actuaría si supiese del cambio, pero sí que le dolería sobremanera saber que la vida que tanto le satisfizo forjar y transcurrir, hoy ya no hay nadie que quiera vivirla. La vemos idealizadora de un régimen siempre presente y al que no renuncia ni le sugiere desencanto a pesar de ser otra cosa que lo prometido, que tuvo que resistir revueltas como las de Hungría, Polonia y Checoslovaquia; y que a la vista, han llevado ya a muchos de sus camaradas a gritar con todas sus fuerzas: Good bye Lenin!

\section{A modo de cierre: Simetría imperfecta}

Despertarse y vivir en otro mundo parece pertenecer más a una utopía propia de historias creadas por Ray Bradbury o Isaac Asimov que a la rea- lidad que vivimos. Sin embargo, el realizador Wolfgang Becker nos muestra en Good bye Lenin! cómo el proceso de unificación alemana que el mundo vivió bien despierto y los alemanes con goce, desilusión o apatía, y que ello no fue ajeno a ningún espectador o partícipe, también puede analizarse abstrayéndose y concibiéndolo como un gran universo onírico que se desplegaba a nuestras espaldas.

Es admirable cómo el arte explora de manera única esa "posibilidad necesaria" de extraer de procesos que el mundo los vivió como políticos y económicos, donde los acuerdos burocráticos son el condimento esencial, historias exiguas que consiguen despertar nuestro sentir y pensar de modo que solo él puede lograrlo.

A la vez, es posible hallar dentro de este maremagno de mensajes semióticos, como es un filme con tal carga de realidad, críticas al poder, a los manejos de la sociedad tratada como un número, y a las pasiones tomadas como resfríos que se pueden "sanar" en una semana.

Es manifiesta la dimensión sentimental que el filme plantea en torno a ideologías políticas. De este modo el socialismo, en contraposición al capitalismo, había creado no solo un sistema político sino una simbología, un lenguaje, una cultura; en definitiva, una manera de ver el mundo. Este aspecto, que se expresa desde la comunión de sus seguidores con el mote de "camaradas" hasta la ilusión de la 
superioridad internacional, hace del socialismo una cosmovisión emparentada más con una ficción que con una realidad.

El filme nos muestra a Cristianne, una ferviente socialista, enarbolando su ideología como la que es llamada a combatir la desigualdad y la injusticia. Somos testigos, desde Good bye Lenin!, de un aspecto interesante de un escenario ya conocido, somos espectadores de la ilusión creada por aquel "segundo mundo", en el que no solo se podía soñar con ser astronauta, sino que hasta se podía serlo.

Asimismo, Becker no deja de bucear en las aguas conflictivas del socialismo y de expresar, en una escena central del filme, una manifestación a favor de mayores libertades. Demuestra con ello una decadencia ideológica que no contenta al total de la población, en donde incluso ex partidarios "jubilados" o hijos de camaradas, como el caso de Álex, participan en las marchas. Del mismo modo, hace referencia al tema de la fuga a Occidente, recuérdese al padre de Álex que desde hace tiempo se mudó al oeste, donde vive disfrutando los "beneficios" del "progreso".

De esta manera queda planteado el conflicto de una simetría imperfecta entre las dos mitades del mundo durante gran parte del siglo $\mathrm{XX}$ : la que goza de aquel "progreso" convertido en nuevo mito, como sostienen Adorno y Horkheimer (1970) el pensamiento Iluminista, que avala filosóficamente el individualismo y la perfectibilidad del hombre mediante el progreso, contradice la crítica que realizaba al período de la Edad Media al que consideraban oscuro, supersticioso y mitológico. Así, ven que en los conceptos de naturaleza, historia, y principalmente en el de progreso, el Iluminismo plantea nuevos mitos de los que no puede escapar, sustentados por la producción en serie, el vestuario moderno, la variedad de productos, y una moral religiosa en donde escudarse. Mientras que la desgastada ideología socialista se presenta como una ilusión de pocos, que pretenden seguir manteniendo una vida errante que pronto deberá convertirse en un híbrido entre economía de mercado e ideales vencidos. Aclaramos que no a causa del triunfo de una de las mitades, entendemos, se produce la asimetría, ni que es favorable a este sector. Por el contrario, cuando no se renuncia a las ideas, como en el caso de Cristianne, cuando tienen un contenido y no son solo una manipulación totalitaria o un simple cúmulo de recetas de mercado, persisten y es allí donde se inclina la balanza: ante convicciones que a diferencia de los procesos y las personas se asientan perennes en la vida y son rescatadas por la historia y por el devenir.

En el filme vemos una lograda exhortación a la conciencia colectiva sobre en qué medida los procesos políticos y económicos despiertan una pasión desmesurada en algunos casos, 
que en momentos decisivos demuestran lo ajenos que son los ciudadanos para esta maquinaria burocrática que en nombre de ellos traiciona sus propias bases, y releva las ideas a la historia mediante una ineptitud y un azar de los que es presa.

Aunque podríamos simplificar el fin del agudizado antagonismo entre este-oeste con la proclamación de un triunfo capitalista, aggiornando la idea de Marx y sosteniendo que todo lo que parece y se presume sólido definitivamente se desvanece en el aire, el socialismo sería algo así como el triunfador en su capacidad de saber articular circunstancias históricas con ideales de vivir mejor a pesar de los posteriores manejos, como lo fueron al final de la Primera Guerra para Lenin y al final de la Segunda Guerra para tantos otros, por elección o imposición, como lo seguirá siendo para todos aquellos que, a pesar de ser "capitalistas" en su modo de vida heredado y hegemónico (como todos nosotros en la actualidad) no dejen de creer que el otro mundo no fue menos sólido que este y que la premisa de Marx todavía debe tenerse en cuenta, y sobre todo ante la soberbia de procesos histórico-sociales que se contradicen a sí mismos creyéndose eternos.

\section{Filmografía}

Becker, Wolfgang (2003). Good bye Lenin! Alemania.

\section{Bibliografía}

Adorno, Theodor y Max HorkHeimer (1970). Dialéctica de la Ilustración. Buenos Aires: Sur.

Bauman, Zygmunt (2002). Modernidad líquida. México: Fondo de Cultura Económica.

Benjamin, Walter (2007). Conceptos de filosofía de la historia. Buenos Aires: Terramar.

Bourdieu, Pierre (1998). La distinción. Criterio y bases sociales del gusto. Madrid: Taurus.

Foucault, Michel (2001). Las palabras y las cosas. Madrid: Siglo XXI Editores.

SARLo, Beatriz (2004). Escenas de la vida posmoderna. Intelectuales, arte y videocultura en la Argentina. Buenos Aires: Seix Barral. 